\title{
Cachaça: Um produto Histórica e Quimicamente Brasileiro
}

\section{Cachaça: A Historical and Chemically Brazilian Product}

DOI: $10.46814 /$ lajdv3n1-002

Recebimento dos originais: 30/10/2020

Aceitação para publicação: 23/12/2020

\section{Angélica Ramos da Luz}

UNESP - Instituto de Química

Rua prof. Francisco Degni, 55 - Araraquara, SP, CEP: 14.80-060

\section{Elias de Souza Monteriro Filho}

UNESP - Instituto de Química

Rua prof. Francisco Degni, 55 - Araraquara, SP, CEP: 14.80-060

\section{Raul Natale Junior}

UNESP - Instituto de Química

Rua prof. Francisco Degni, 55 - Araraquara, SP, CEP: 14.80-060

\section{Miguel Ruiz}

UNESP - Instituto de Química

Rua prof. Francisco Degni, 55 - Araraquara, SP, CEP: 14.80-060

\section{João Bosco Faria}

UNESP - Faculdade de Ciências Farmacêuticas

Rod. Araraquara - Jaú Km 1, - Araraquara, SP, CEP. 14801-902

E-mail: fariajb@fcfar.unesp.br

\section{Sinara München}

UFSM - PPG Educação em Ciências: Química da Vida e Saúde Av. Roraima, 1000, Santa Maria-RS CEP 97105900

E-mail: sinaramunchen@yahoo.com.br

\section{Martha B. Adaime}

UFSM - PPG Educação em Ciências: Química da Vida e Saúde

Av. Roraima, 1000, Santa Maria-RS CEP 97105900

\section{Leinig Antonio Perazolli}

UNESP - Instituto de Química

Rua prof. Francisco Degni, 55 - Araraquara, SP, CEP: 14.80-0060

E-mail: leinig.perazolli@ unesp.br 


\section{RESUMO}

O início da produção da cachaça remete ao Ciclo do Açúcar, com o processo de destilo das sobras do melaço fermentado de cana. Quando as Antilhas ampliam a produção do açúcar, ocorre a desvalorização do produto brasileiro, o que da início a destilação direta do caldo fermentado. A diferença de matéria prima em relação ao Rum e das madeiras utilizadas para o envelhecimento da bebida permitem concluir que a cachaça é um produto com raízes genuinamente brasileiras.

Palavras-chave: História, Química, Cachaça.

\section{ABSTRACT}

The beginning of the production of cachaça refers to the Sugar Cycle, with the process of distilling the leftovers of fermented cane molasses. When the West Indies increase the production of sugar, there is the devaluation of the Brazilian product, which from the beginning the direct distillation of the fermented juice. The difference of raw material in relation to the Rum and the woods used for the aging of the drink allow the conclusion that the cachaça is a product with genuinely Brazilian roots.

Keywords: History, Chemistry, Cachaça.

\section{INTRODUÇÃO}

O Decreto $\mathrm{n}^{\mathrm{o}} 4.062$, de 21 de dezembro de 2001 determinou oficialmente que a cachaça é uma bebida genuinamente brasileira, com graduação alcoólica de $38 \%$ a $48 \%$ a $20^{\circ} \mathrm{C}$, obtida pela destilação do caldo fermentado, mosto, de cana de açúcar com características sensoriais típicas com adição de até $6 \mathrm{~g} / \mathrm{l}$ de açúcares expressos em sacarose. A cachaça é a segunda bebida mais consumida no país, com uma produção estimada em 1,4 bilhões de litros em 2011 e por cerca de 40 mil produtores, gerando 600 mil empregos direta e indiretamente. É constituída essencialmente de etanol (Figura 1a) e água, além de outros compostos, como álcoois superiores, ácidos, ésteres, acetais, fenóis, hidrocarbonetos, compostos nitrogenados, sulfurados e açúcares (Odello et al, 2009). A Figura 1 ilustra a estrutura química do etanol $\left(\mathrm{CH}_{3} \mathrm{CH}_{2} \mathrm{OH}\right)$ (função álcool), do acetaldeido $\left(\mathrm{CH}_{3} \mathrm{CHOH}\right)$ (função aldeído) e do acetato de etila $\left(\mathrm{CH}_{3} \mathrm{COOCH}_{2} \mathrm{CH}_{3}\right)$ (função éster).

A bebida é muito apreciada por apresentar sabor e aroma característicos, provenientes dos processos fermentativos, de destilação e envelhecimento no decorrer de sua produção. As características organolépticas se dão pela presença de pelo menos $1 \%$ em massa de compostos secundários, como álcoois superiores, ésteres, ácidos carboxílicos e compostos carbonílicos, que são importantes na constituição do aroma e sabor (NASCIMENTO et al. 1998). Os sabores diferenciados da cachaça provem da destilação direta do caldo fermentado, que acrescenta produtos químicos específicos como o propanol, isobutanol e álcool isoamílico, além de íons de magnésio $\left(\mathrm{Mg}^{2+}\right)$ e manganês $\left(\mathrm{Mn}^{2+}\right)$ os quais estão presentes em menor concentração no Rum produzido pela fermentação do melaço. Estes produtos são arrastados do caldo durante a cristalização do açúcar e estão presentes no melaço em menor concentração. (AQUINO et al. 2008). 
Figura 1. (a) Molécula do etanol, (b) molécula do acetaldeido e (c) molécula acetato de etila.

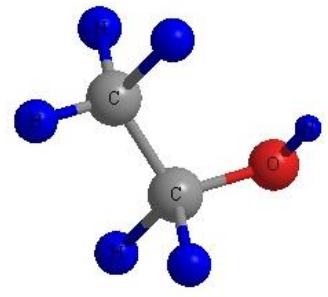

(a)

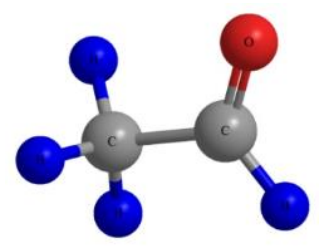

(b)

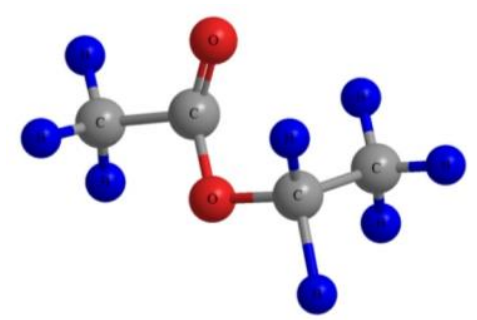

(c)

Considerando a importância desse produto no cenário histórico, econômico e social brasileiro e a possibilidade de sua abordagem no ensino de química, este trabalho tem como objetivo realizar um estudo histórico e químico da cachaça que possa ser referência para o estudo do tema, assim como para planejamento de atividades didáticas. Também, considerando que a desinformação sobre a química pela sociedade em geral ilustra que a formação dos químicos deve incorporar analises históricas, filosóficas e sociológicas sobre o empreendimento científico, bem como os valores que o regem, levando aos professores a lecionar não somente conteúdos e a entender o que o conheciemtno químico tem de caracterísitco e o que o fez ser valorizado (HAAG, 2013)

\section{A cana-de-açúcar chega ao Brasil}

Por volta do século XVI, época em que o açúcar (diossacarídio formado pela união de uma glicose com uma frutose, Figura 4a), possuía um imenso valor comercial, Portugal deu início a produção de açúcar nas colônias que havia conquistado durante o período das grandes navegações. Para viabilizar tal projeto, além do plantio da matéria-prima, foi necessária a construção de engenhos para do produto. No Brasil, as principais áreas de produção foram inicialmente o litoral da região Sudeste e Nordeste, locais onde haviam condições climáticas favoráveis e recursos para custear a produção. O sistema de colonização voltado para o plantio de cana desenvolveu uma economia e uma sociedade local com diversas características culturais moldadas por essa estrutura, tais como as festas realizadas durante as épocas de plantio e colheita, por exemplo as festas juninas, Figura 2a, assim como um modelo familiar centrado na figura patriarcal, Figura 2b, do senhor de engenho (MIRANDA, 2008). 


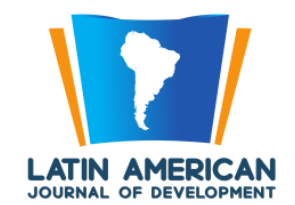

Figura 2: a) Festa Junina retratada por Anita Malfatti, (b) Quadro de Jean-Baptiste Debret que retrata a estrutura social patriarcal do Brasil colonial

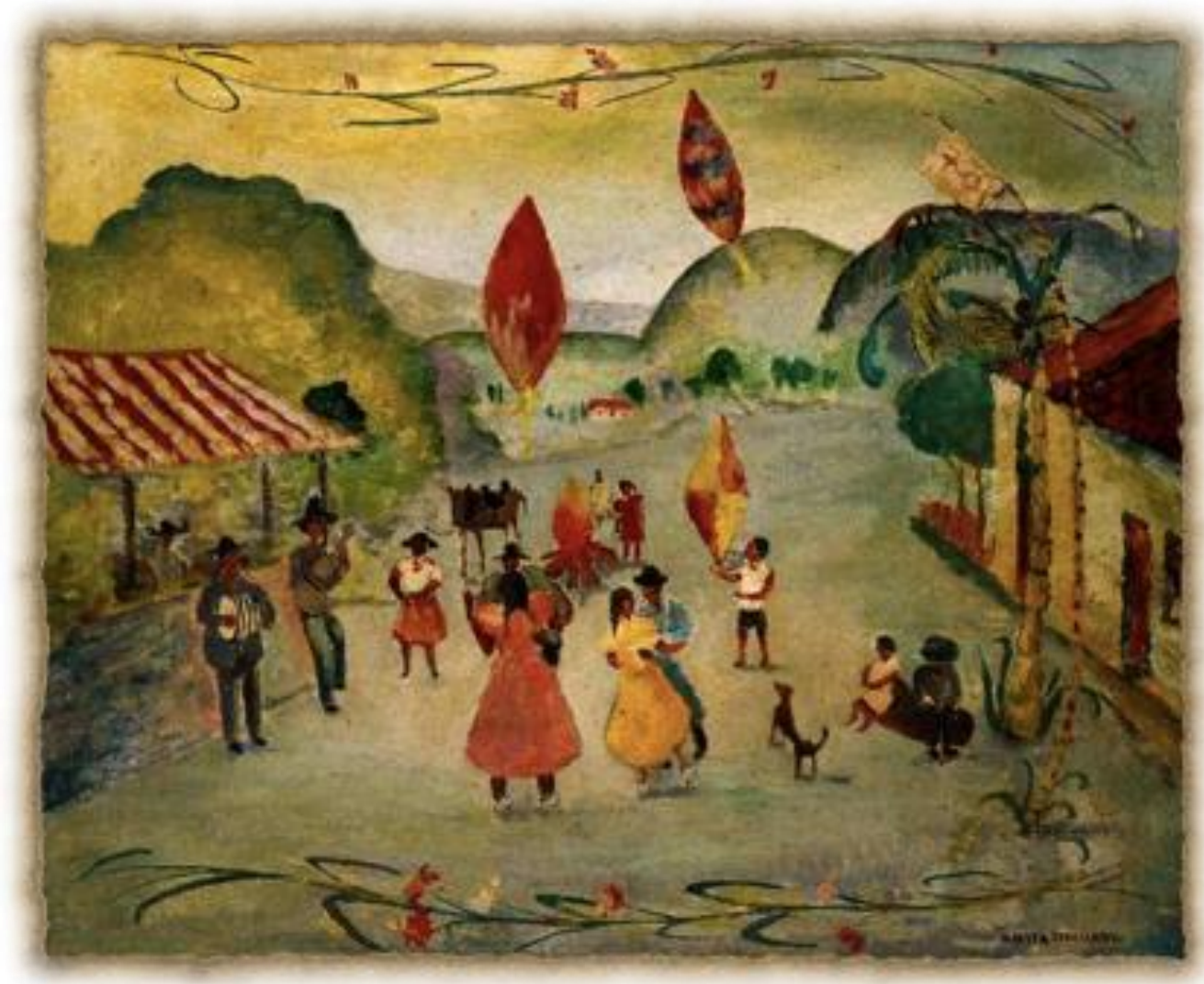

(a)

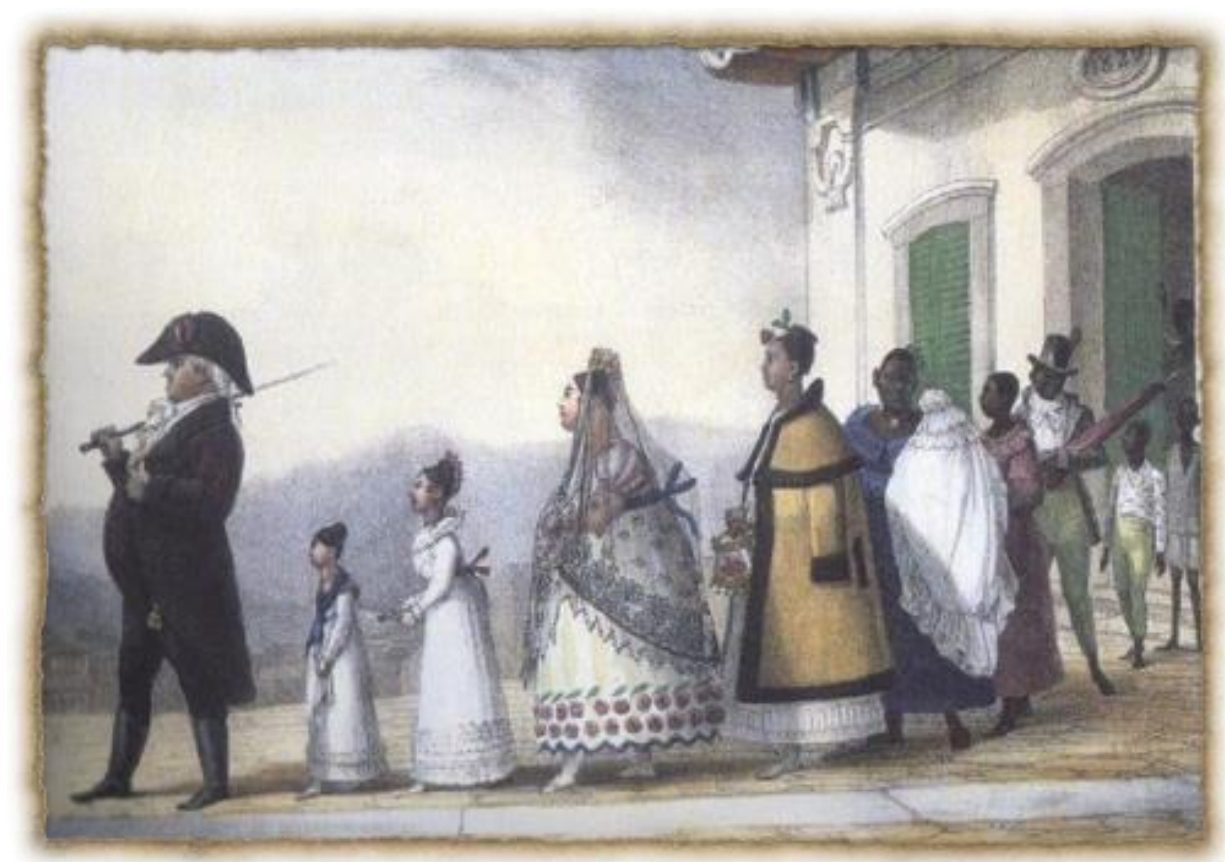

(b) 


\section{A aguardente de cana no período colonial}

Durante o Ciclo do Açúcar no período colonial, o açúcar era obtido através de sua cristalização diretamente do caldo de cana cozido. Uma parte deste caldo despejado nas formas não se cristaliza, o melaço, que então era acumulado em piscinas embaixo das formas de cristalização na Casa de Purgar, Figura 3. As tentativas de se reaproveitar o melaço resultaram na deterioração do produto e perda da produção, o que levou o melaço não cristalizado a ter outros destinos, como a alimentação dos porcos ou cachaços (levando a uma das origens do nome cachaça) e a destilação para a produção de aguardente, o que garantia uma renda extra ao Senhor do Engenho (PINHEIRO et $a l ., 2003)$. Nesta época, devido ao pacto colonial, toda a estrutura econômica brasileira era baseada na produção do açúcar, que deveria ser exportado exclusivamente para Portugal. Porém por volta do século XVII, a concorrência com o açúcar produzido nas Antilhas, que possuía um menor custo de transporte e uma melhor qualidade, fez com que o preço de mercado sofresse uma sequência de quedas. A desvalorização do açúcar brasileiro foi tamanha que os produtores perderam o interesse no produto. A maneira que os senhores de engenho encontraram de minimizar os prejuízos foi aproveitar a estrutura dos engenhos passar a produzir cachaça. Nesta época a bebida competia com a bagaceira, umaaguardente de vinho portuguesa, tanto no mercado local quanto no escambo de metais nas Minas Gerais e com mercadores africanos que forneciam escravos aos portugueses (MIRANDA, 2008).

Figura 3: Interior da Casa de Purgar, ilustrando as formas de cristalização, e ao final do processo o melaço escorria para piscina logo abaixo e o açucar era retirado, entornando a forma e formando os pães de açúcar (FUNDAÇÃO JOAQUIM NABUCO, 2006).

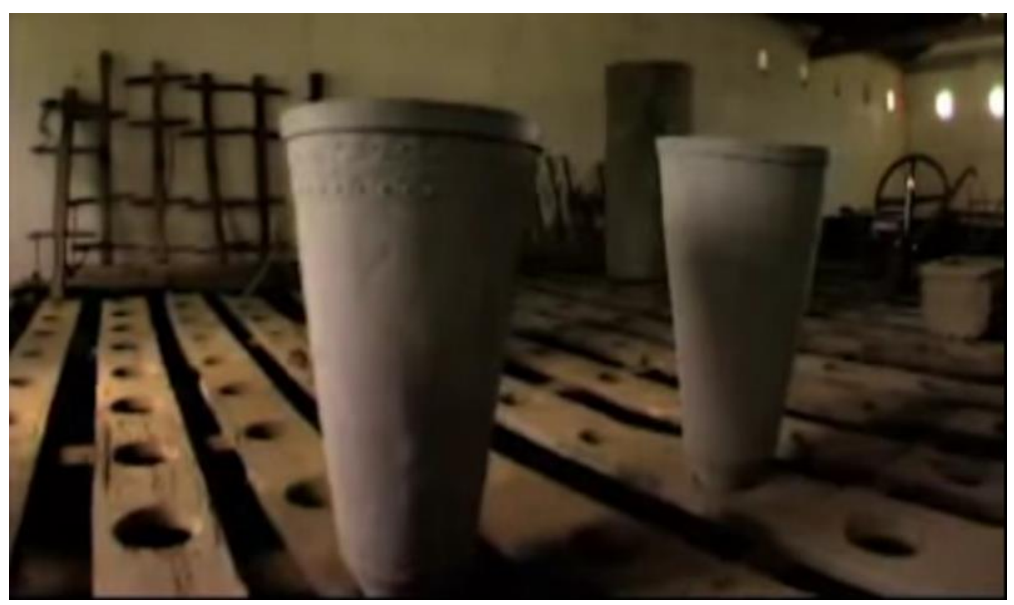

\section{Plantio e Colheita da Cana de Açúcar}

É de grande importância a etapa relacionada ao plantio da cana de açúcar, pois tanto o rendimento quanto a qualidade do produto final dependem diretamente da variedade da cana plantada, das condições do solo e das condições climáticas, além do tempo de maturação da cana. De 
modo geral, quando a variedade é adequada para produção de açúcar e álcool, também será para a produção da cachaça, posto que o principal produto presente na cana de açúcar é a sacarose, Figura 4a. Para um bom rendimento da extração da sacarose, é essencial que a colheita da cana seja feita quando os colmos da planta estiverem maduros, situação na qual o acúmulo de sacarose está em seu ponto máximo. Atualmente a técnica de colheita da cana ainda costuma incluir o uso da queimada, procedimento que tem como consequência a formação do furfural, devido a quebra da sacarose em glicose e frutose (uma pentose), associada à desidratação ácida das pentoses presentes, Figura 4b, (Furfural Chemicals, 2006). A presença do furfural diminui a qualidade da cachaça, uma vez que, além de tóxico, provoca um sabor desagradável ao produto.

Figura 4: (a) Molécula da sacarose ilustrando a união de uma molécula de glicose com uma de pentose, (b) Molécula do furfural.

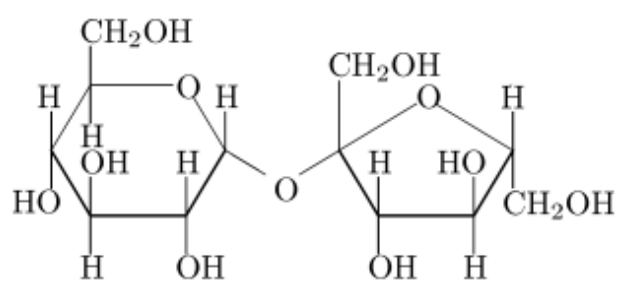

(a)

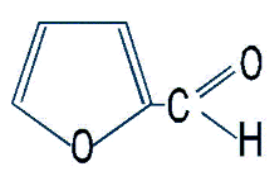

(b)

\section{Preparação do Caldo e Fermentação}

É importante destacar, neste ponto, que a cachaça é produzida através da fermentação do caldo de cana, diferenciando-se de outras aguardentes de cana, como o rum, que é produzido a partir da fermentação do melaço, subproduto da produção de açúcar. A preparação do caldo pode ser resumida nas etapas de filtração do caldo, adequação de seu BRIX e do pH (BRIX é uma escala numérica de índice de refração utilizada para determinar a quantidade de compostos solúveis numa solução de sacarose).

Após passar pela moenda, o caldo é filtrado em várias peneiras de malha fina, pra eliminar os bagacílhos e outras impurezas sólidas. Depois disso, o caldo é diluído até que seu BRIX fique em torno de 14 a 16, ideal para que o processo de fermentação ocorra com o rendimento máximo. Após a fervura do caldo é inserida a levedura Saccharomyces cerevisiae, responsável pela transformação dos açúcares presentes em etanol e outros voláteis denominados compostos secundários. Então o caldo, agora chamado de mosto, é inicialmente fermentado na presença de oxigênio $\left(\mathrm{O}_{2}\right)$, que depois de consumido pela levedura em seu processo de reprodução, inicia a fermentação anaeróbia, etapa na qual as enzimas das leveduras presentes no mosto transformam o açúcar em etanol, com 
desprendimento de gás carbônico $\left(\mathrm{CO}_{2}\right)$, conforme as reação 1 nesta reação bioquímica a enzima invertase quebra a sacarose em glicose e frutose e que depois são degradadas à etanol e dióxido de carbono, reação 2 (LALUCE, 1995).

$$
\begin{gathered}
\mathrm{C}_{12} \mathrm{H}_{22} \mathrm{O}_{11}+\mathrm{H}_{2} \mathrm{O} \\
\begin{array}{c}
\text { (sacarose) } \\
\text { (glicose e frutose) }
\end{array} \\
2 \mathrm{C}_{6} \mathrm{H}_{12} \mathrm{O}_{6} \stackrel{\text { invertase }}{\longrightarrow} 2 \mathrm{C}_{6} \mathrm{H}_{12} \mathrm{O}_{6} \\
(\text { glicose })
\end{gathered}
$$

A fermentação avança enquanto houver a formação e liberação de bolhas de $\mathrm{CO}_{2}$ do mosto. $\mathrm{O}$ processo costuma durar entre 16 e 24 horas e a levedura utilizada é então decantada, podendo ser aproveitada para futuras fermentações, nesta etapa o caldo passa a denominar-se vinho, com a concentração de etanol em torno de $9 \%$ e segue para a destilação. É na fermentação do caldo de cana que também são formados os chamados compostos secundários, como aldeídos e ésteres (Figura 1b e 1c), que são fundamentais na definição do sabor e aroma da cachaça (SAFFIOTI, 1968). São formados diferentes ésteres como acetato de etila (característica de abacaxi), butanoato de etila (frutado de banana/maçã); hexanoato de etila (vinho); lactato de etila (pêra); octanoato de etila (floral); nonanoato de etila (maçã/uva); decanoato de etila (doce/ frutado), octanoato de isoamila (Côco) e dodecanoato de etila (floral/frutado). Também há formação de outros produtos como isobutanol e álcool isoamílico, caracterísiticos da fermentação do caldo de cana e destilação do vinho. A formação de um ou mais ésteres é função das características da cana, do processamento do caldo, do tipo de levedura utilizado, da temperatura da dorna e de todos os processos envolvidos na fermentação (CARDOSO, 2012).

A fermentação direta do caldo de cana com posterior destilação do vinho leva também à obtenção de uma maior concentração de íons de cálcio, de cobre, de magnésio e de manganês na cachaça, que são características químicas da cachaça. Para o Rum estes íons estão presentes em menor concentração pois são eliminados por arraste durante o processo de cristalização do açúcar (AQUINO et al. 2008). 


\section{Destilação}

Após o processo de fermentação, ocorre a etapa da destilação em alambique ou em coluna de destilação, no qual ocorre a separação dos componentes com diferentes pontos de ebulição. Para a produção de cachaça pode se utilizar o processo destilação contínuo em colunas de destilação ou a destilação descontínua ou batelada em alambique de cobre, onde o vinho é fervido e os vapores produzidos são condensados. No processo descontínuo, utilizado pela maioria dos pequenos e médios produtores, do condensado produzido são separadas três partes: a cabeça, o coração e a cauda. Na cabeça, primeira fração destilada, que corresponde a cerca de $10 \%$ do volume total do destilado, é encontrada a maior parte dos voláteis como o metanol, álcool formado por apenas um carbono $\left(\mathrm{H}_{3} \mathrm{COH}\right)$, altamente tóxico que é originado através da degradação da pectina, polissacarídeo encontrado na cana-de-açúcar na etapa de fermentação (ZACARONI et al. 2011). Mesmo em quantidades relativamente pequenas provoca a famosa "ressaca" com acentuada dor de cabeça, em concentrações mais elevadas pode provocar cegueira e até a morte. Outro produto presente nesta parte é o acetaldeído, composto também indesejável devido as suas características sensoriais agressivas. O coração é a parte utilizada na fabricação da cachaça, corresponde a cerca de $80 \%$ do destilado, e é constituído basicamente pelo etanol, ésteres e pequena concentração de aldeídos, os quais serão esterificados no envelhecimento. A última parte é a cauda, formada por ácidos e álcoois superiores, correspondente a cerca de $10 \%$ do volume total.

O cobre, presente na constituição dos alambiques de qualidade, tem a importante função ao atuar como catalisador na formação de ésteres e outros compostos desejáveis e na eliminação do dimetilsulfeto $\left(\mathrm{CH}_{3} \mathrm{SCH}_{3}\right)$, Figura 5a, formado a partir de compostos contendo enxofre durante o processo que é o responsável pelo odor desagradável de cachaça destiladas em destiladores de aço inox. Porém, o efeito colateral do uso do cobre é a formação de um resíduo esverdeado nas paredes do alambique, o carbonato básico de cobre, conhecido como zinabre ou azinhavre, de acordo com a reação 3, que contamina o destilado por dissolução ácida reduzindo a qualidade do produto obtido, deixando a cachaça com gosto zinabrado (ESPINOZA e BOTELHO, 2006). Para minimizar a formação deste resíduo é necessário manter uma higienização adequada do alambique, por exemplo, o alambique pode ser lavado com água e caldo de limão, que por sua natureza ácida, presença de íons $\mathrm{H}^{+}$, ajuda na dissolução do zinabre, conforme reação 4 (Cardoso, 2012).

$$
\begin{gathered}
2 \mathrm{Cu}_{(\mathrm{s})}+\mathrm{O}_{2(\mathrm{~g})}+\mathrm{H}_{2} \mathrm{O}_{(\mathrm{g})}+\mathrm{CO}_{2(\mathrm{~g})} \rightarrow \mathrm{Cu}_{2}(\mathrm{OH})_{2} \mathrm{CO}_{3(\mathrm{~s})} \\
\mathrm{Cu}_{2}(\mathrm{OH})_{2} \mathrm{CO}_{3(\mathrm{~s})}+4 \mathrm{H}^{+}{ }_{(\mathrm{aq})} \rightarrow 2 \mathrm{Cu}^{2+}{ }_{(\mathrm{aq})}+3 \mathrm{H}_{2} \mathrm{O}_{(\mathrm{l})}+\mathrm{CO}_{2(\mathrm{~g})}
\end{gathered}
$$


O cobre tem seu limite máximo estabelecido pelo Ministério da Agricultura, Pecuária e Abastecimento em $5 \mathrm{mg} / \mathrm{L}$, entretanto no mercado internacional este valor é de $2 \mathrm{mg} / \mathrm{L}$, o que dificulta a exportação da bebida, e mesmo que o limite nacional não seja considerado tóxico, pode acentuar o sabor ácido e permitir processos oxidativos pela presença de íons cobre (ZACARONI et al. 2011). Embora o cobre seja essencial para processos metabólicos, pode ser tóxico por sua afinidade com grupos S-H de proteínas e enzimas, e por isso é vinculado a epilepsia, melanoma, artrite reumatóide e perda do paladar (LIMA et al. 2006).

\section{Envelhecimento}

O envelhecimento da cachaça é um importante parâmetro para a melhoria de sua qualidade sensorial, uma vez que esta etapa afeta a intensidade da cor desde amarelada até marrom brilhante, adiciona sabor de madeira, sabor doce e o aroma de frutas, também diminui os fatores considerados negativos, como a acidez, o sabor seco de álcool e o amargor (OTELLO et al. 2009), além de diminuir o teor de cobre (MIRANDA; MARTINS, 2008). Durante o processo de estocagem da cachaça, se considera como processo de envelhecimento somente a situação na qual o produto é armazenado em recipientes de madeira. Os tipos de madeira mais escolhidos para a construção dos tonéis são o bálsamo, jatobá, umburana, canéla-sassafras, jequitibá, ipê amarelo ou amendoim. Nesta etapa, o contato da bebida com a madeira do tonel irá gradativamente provocar diversas reações químicas que alterarão a cor, o sabor e o aroma do produto final. Devido a semipermeabilidade da madeira, o processo de envelhecimento permite tanto a perda ao ambiente de determinados componentes como a água e o etanol, quanto a entrada do oxigênio, permitindo a ocorrência do processo de oxidação dos aldeídos e álcoois superiores gerados na fermentação do mosto. Dentre os compostos provenientes da madeira que são incorporados a bebida, estão os compostos fenólicos, flavonóides (Rutina-Figura 5b) e taninos (DEWIK, 2002), assim como produtos da decomposição parcial de macromoléculas, como lignina, Figura 5c, e celulose em monômeros solúveis como aldeídos e ácidos fenólicos (TRINDADE, 2006; VENTURA; GIRALDEZ, 2006). 


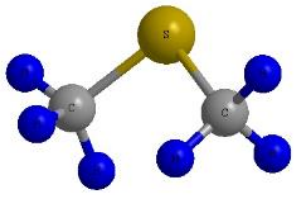

(a)

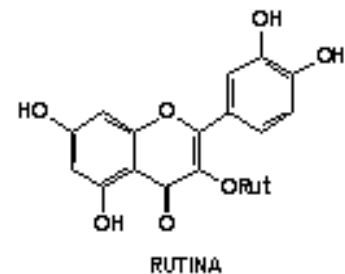

(b)

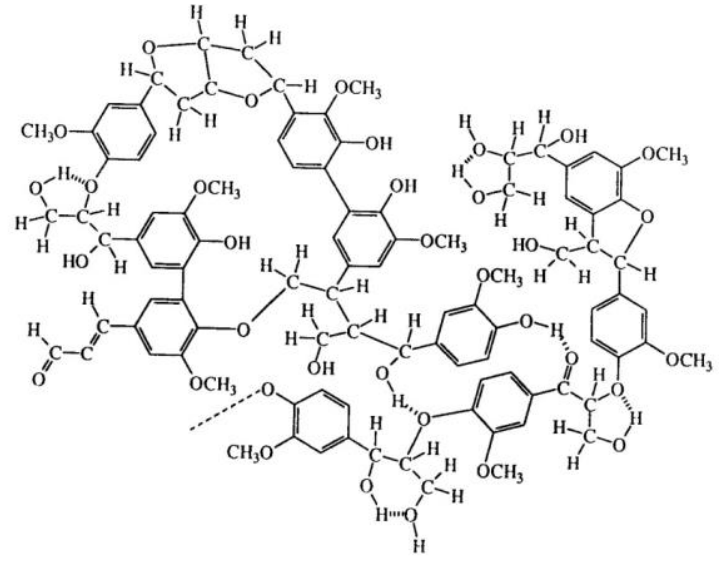

(c)

Todas as reações químicas e os processos de dissolução de compostos da madeira durante o envelhecimento da cachaça, assim como de outras bebidas alcoólicas, permitem a formação de grandes aglomerados de moléculas incluindo os ésteres, os álcoois superiores e os aldeídos remanescentes, os quais ficam em equilíbrio com o etanol, o que é notado na forma semelhante a um óleo que escorre em volta do copo logo após ser rodado/agitado para que o líquido molhe as paredes internas. Esta formação é chamada de "choro" ou "lágrimas da cachaça". Este aglomerado é rompido com água liberando todo o aroma e sabor ao ser ingerido.

\section{CONSIDERAÇÕES FINAIS}

Diante da pesquisa apresentada, é possível concluir que os aspectos peculiares relativos à criação e envelhecimento da cachaça permitem afirmar que este é um produto com origens genuinamente brasileiras. Além disso, é possivel trabalhar uma abordagem interdisciplinar em sala de aula buscando programar o interesse em ciênicas e como a História do Brasil e a Química, visto que esta abordagem se dá em torno de temas sociais centrados e podem levar a participação efetiva de estudantes, desenvolvendo conceitos de forma interdisciplinar e contínua ao considerar as diversas dimensões do tema em questão. 


\section{REFERÊECIAS}

AQUINO, F.W.B.; BOSO, L. M. ; CARDOSO, D. R. ; FRANCO, D. W. . Amino acids profile of Brazilian sugar cane spirit (Cachaça), Rum, and Whiskey. Food Chemistry, v. 108, p. 784-793, 2008. CARDOSO, D.R. Aspectos da Química da Aguardente. www.semanadaquimica.org, acessada em Agosto de 2012.

ESPINOZA, L.J.S., BOTELHO, M.S., Boas Práticas de Fabricação para Estabelecimentos Produtores de Cachaça: Aspectos Higiênico-Sanitários. Lavras: Editora UFLA/FAEPE, 2006.

FUNDAÇÃO JOAQUIM NABUCO. A Cultura do Açúcar, Fundação Joaquim Nabuco/ Massagana Multimídia Produções, episódio 1, 2006.

HAAG, CARLOS Nada se perde, tudo se transforma, Revista FAPESP, Edição 208, p. 79-81, Junho de 2013.

LALUCE, C. Considerações gerais sobre a fermentação alcoólica na produção da aguardente artesanal de cana. O Engarrafador Moderno, n. 42, 1995

NASCIMENTO, R.F. et al. Influência do material do alambique na composição química das aguardentes de cana-de-açúcar. Química Nova, v. 21, n.6, 1998.

ODELLO, L. et al. Avaliação sensorial de cachaça. Q. Nova, v.32, n.7, SP, 2009.

PINHEIRO, P.C., LEAL, M.C., ARAUJO, D.A. Origem, Produção e Composição Química da Cachaça. Química Nova na Escola, n. 18, novembro 2003.

SAFFIOTI, W. Fundamentos de Química. Cia Ed. Nacional. São Paulo, Brasil; 1968

TRINDADE, A.G., CACHAÇA: Um Amor Brasileiro. Ed. Melhoramentos, 2006.

VENTURA, S., GIRALDEZ, R., Cachaça - Cultura e Prazer do Brasil. 1 ${ }^{a}$ Edição, Damara Editora Ltda, 2006.

ZACARONI, L. M. et al. Caracterização e quantificação de contaminantes em aguardentes de cana. Química Nova, v.. 34, n. 2, 320-324, 2011. 